reported suicide attempt were analysed by using a logistic regression model.

Results The prevalence of suicide attempt was $2.7 \%$ and was significantly higher in women than in men (4.6\% vs. $0.9 \%), 65 \%$ used sharp objects, while $26 \%$ and $5 \%$ drug poisoning and hanging, respectively. Almost 19\% reported requiring medical and/or psychiatric services. $28 \%$ of the states of Mexico report prevalences betwen $3.5-5.2 \%$. Variables statistically significant in the model were: age in years $\left(\mathrm{OR}_{\mathrm{A}}=7.57 ; 95 \% \mathrm{CI}:=4.73-12.10\right)$, quadratic age $\left(\mathrm{OR}_{\mathrm{A}}=0.93 ; 95 \% \mathrm{CI}:=.92\right.$ to .94$)$, schooling in years $(\mathrm{OR}=0.90 ; 95 \% \mathrm{CI}:=0.85$ to 0.95$)$, women $\left(\mathrm{OR}_{\mathrm{A}}=6.3 ; 95 \% \mathrm{CI}:=4.94-8.06\right]$, social security $\left(\mathrm{OR}_{\mathrm{A}}=0.80 ; 95 \% \mathrm{CI}:=0.65\right.$ to 0.98$]$ not currently drinking alcohol $\left(\mathrm{OR}_{\mathrm{A}}=2.25 ; 95 \% \mathrm{CI}:=1.74-2.91\right)$ and currently $\left(\mathrm{OR}_{\mathrm{A}}=2.29 ; 95 \% \mathrm{CI}:=1.74-3.01\right)$, not currently smoking tabacco $\left(\mathrm{OR}_{\mathrm{A}}=2.72 ; 95 \% \mathrm{CI}:=2.11-3.51\right)$ and currently $\left(\mathrm{OR}_{\mathrm{A}}=3.2695 \% \mathrm{CI}:=2.48-4.27\right)$, health damage due to interpersonal violence $\left(\mathrm{OR}_{\mathrm{A}}=4.35 ; 95 \% \mathrm{CI}:=3.27-5.80\right)$, having a mild $\left(\mathrm{OR}_{\mathrm{A}}=1.50 ; 95 \% \mathrm{CI}:=1.12-2.01\right)$ and moderate eating disorder $\left(\mathrm{OR}_{\mathrm{A}}=4.22 ; 95 \% \mathrm{CI}:=3.21-5.54\right)$ and being a second degree relative (grandson, nephew, etc) $\left(\mathrm{OR}_{\mathrm{A}}=1.42 ; 95 \%\right.$ $\mathrm{CI}:=1.50-1.77)$.

Conclusions The variables related to suicide attempt are those related to social factors, psychiatric disorders and violence. Studies in Mexico report that a high percentage of adolescents with suicide attemptes have psychiatric disorder. It is urgent to have a better diagnostic and treatment of these disorders.

\section{IMPACT OF ECONOMIC AUSTERITY AND PROSPERITY EVENTS ON SUICIDE IN GREECE: A 30-YEAR INTERRUPTED TIME-SERIES ANALYSIS}

${ }^{1}$ Charles C Branas, ${ }^{2}$ Anastasia E Kastanaki, ${ }^{2}$ Manolis Michalodimitrakis, ${ }^{3}$ John Tzougas, "Elena F Kranioti, ${ }^{5}$ Pavlos N Theodorakis, ${ }^{1}$ Brendan G Carr, ${ }^{1}$ Douglas J Wiebe. ' University of Pennsylvania, Perelman School of Medicine, Philadelphia, USA; ${ }^{2}$ Faculty of Medicine, University of Crete, Iraklion, Greece; ${ }^{3}$ Hellenic Statistical Authority, Piraeus, Greece; ${ }^{4}$ Edinburgh Unit for Forensic Anthropology, SHCA, University of Edinburgh, UK; ${ }^{5}$ WHO National Counterpart for Mental Health, Athens, Greece

\subsection{6/injuryprev-2016-042156.67}

Background The recent strain on the Greek public has prompted academic discussion of the potential health effects of the austerity measures. In this regard, suicides in Greece have been a lead topic, with numerous commentators concluding that the recent austerity measures have led to increased suicides in Greece. This conclusion has, however, been appropriately met with scepticism and no large-scale, systematic longitudinal analysis has been completed to inform the ongoing debate as to whether austerity measures have led to statistically higher suicide rates in Greece.

Methods National data from the Hellenic Statistical Authority were assembled as 360 monthly counts of: all suicides ( $\mathrm{n}=11505)$, male suicides $(\mathrm{n}=9079)$, female suicides $(\mathrm{n}=2426)$ and all suicides plus potentially misclassified suicides occurring in Greece from 1983 to 2012. Twelve austerity-related and prosperity-related events that occurred in Greece during the study period were identified and interrupted time-series analyses using ARIMA models and transfer functions were used to test the impact of each event on suicide.

Results In 30 years, the highest months of suicide in Greece occurred in 2012. New austerity measures in June 2011 marked the beginning of significant, abrupt and sustained increases in total suicides $(+35.7 \%, \mathrm{p}<0.001)$ and male suicides $(+18.5 \%$, $\mathrm{p}<0.01)$. Sensitivity analyses that figured in undercounting of suicides also found a significant, abrupt and sustained increase in June $2011(+20.5 \%, p<0.001)$. Suicides by men in Greece also underwent a significant, abrupt and sustained increase in October 2008 when the Greek recession began $(+13.1 \%$, p < 0.01), and an abrupt but temporary increase in April 2012 following a public suicide committed in response to austerity conditions $(+29.7 \%, \mathrm{p}<0.05)$. Suicides by women in Greece also underwent an abrupt and sustained increase in May 2011 following austerity-related events $(+35.8 \%, \mathrm{p}<0.05)$. One prosperityrelated event, the January 2002 launch of the Euro in Greece, marked an abrupt but temporary decrease in male suicides $(-27.1 \%, \mathrm{p}<0.05)$.

Conclusions This is the first multidecade, national analysis of suicide in Greece using monthly data. Select austerity-related events in Greece corresponded to statistically significant increases for suicides overall, as well as for suicides among men and women. The consideration of future austerity measures should give greater weight to the unintended mental health consequences that may follow and the public messaging of these policies and related events.

\section{School Safety}

\section{Parallel Mon 1.2}

\section{IMPLEMENTATION OF THE 'SCHOOL TRAVEL \& CHILD SAFETY SURVEY' FOR DATA LINKAGE RESEARCH}

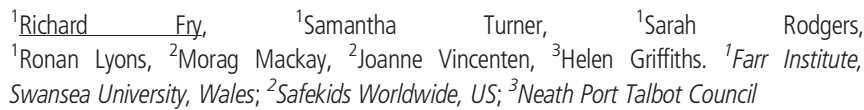

\subsection{6/injuryprev-2016-042156.68}

Background The School Travel and Child Safety Survey (STCSS) was developed as part of the European TACTICS project (Tools to Address Childhood Trauma, Injury and Children's Safety) to address the lack of standardised data on children's safety and exposure to risk across Europe.

Description of the Problem Current methods used to collect data on child safety and exposures to risk are not collected in a coordinated way, making research and policy evaluation in these areas difficult. The STCSS was developed with European partners, as a standardised tool which could be adopted by member states, to collect child safety data and enable comparisons between different regions/countries for policy development and evaluation. Travel behaviour data (e.g. mode of transport and distance travelled) is also limited; but vitally important for monitoring active travel and road safety interventions.

Results The STCSS was developed for children aged 10-13 years to be undertaken in school, and was successfully piloted in 5 countries across Europe $(n=636$, participation rate $=88.37 \%$ ). A sample of children were retested to establish the survey reliability, and per cent agreements were $\geq 96 \%$. The STCSS has been further developed in Wales, to enable the results to be anonymised and incorporated into the Secure Anonymised Information Linkage (SAIL) databank at Swansea University. Data linkage methods within SAIL allow the STCSS results to be linked to other individual and household level datasets; for example, socioeconomic, demographic, health and education data.

Conclusions The ability to link the results from this survey to other routinely collected data in the SAIL database, will provide much needed evidence on the medium and long-term 